\title{
Journal of the American Medical Association.
}

EDITED FOR THE ASSOCIATION BY N. S. DAVIS.

PUBLISHED WEEKLY.

Cinicago, April 24, I886.

No. I7.

\section{ORIGINAL ARTICLES.}

\section{THE TREATMENT OF COMPOUND FRACTURES WIRING AND DRAINAGE.' \\ BY W. P. VERITY, M.D., OP CHICAGO, ILL. \\ SURGHON TO TIIE COOK COUNTY HOSPITAL.}

Bilroth, in an edition of his "Surgical Pathology," written before antisepticism had begun to struggle for an existence, says: "The treatment of complicated fractures is one of the most difficult problems in surgery. We never cease learning on this point." In this view of the case may be found my apology for the introduction of a seemingly exhausted topic for discussion.

In the procedure I am about to describe, there is no single detail which is strictly original, but the procedure as a whole deserves the attention of the profession. When a comminuted fracture comes under my observation, the affected part and its surroundings are carefully cleansed and shaven. Soft parts so ragged and contused, and so situated as to produce separation of the fragments and to act as foreign bodies, are removed; as likewise all foreign bodies; the external wound being enlarged, if necessary, for this pupose. If the part affected be a lower extremity, this is flexed at an obtuse angle. The fragments are then approximated in the most normal position possible. For this purpose projecting sharp points, if denuded and acting as irritants, may be removed, as in Case 4, but an effort should be made to retain all such fragments as means of support, as in Case 2. When the best possible approximation is secured, the fragments are wired or nailed together; silver wire (when of good quality) is preferable, but iron wire is the most attainable and can be readily disinfected by means of heat and rendered properly flexible. Drainage is secured by means of large tubes from the most dependent point. The whole extremity is then covered with an extensive thick antiseptic dressing, and incased in a plaster cast, removable at each dressing. The present procedure has certain very. demonstrable advantages in cases which otherwise could not be treated antiseptically in a thorough manner.

In illustration of these advantages the following cases may be cited. First. All points of bone and

13ead in the Section of Surgery and Anatomy at the Thirty-Sixth Annual Meeting of the American Medical Association. injured tissue fragments, likcly to act as irritants, are removed, except where bone point is needed for mechanical support. This is well illustrated by the fol lowing case:

Case $1 .-$ C. W. S., white, aged 39 ; a painter; had a recurrent attack of erysipelas, but no venereal disease; he fell from a scaffold, stustaining a compound comminuted fracture of the tibia and fibula.

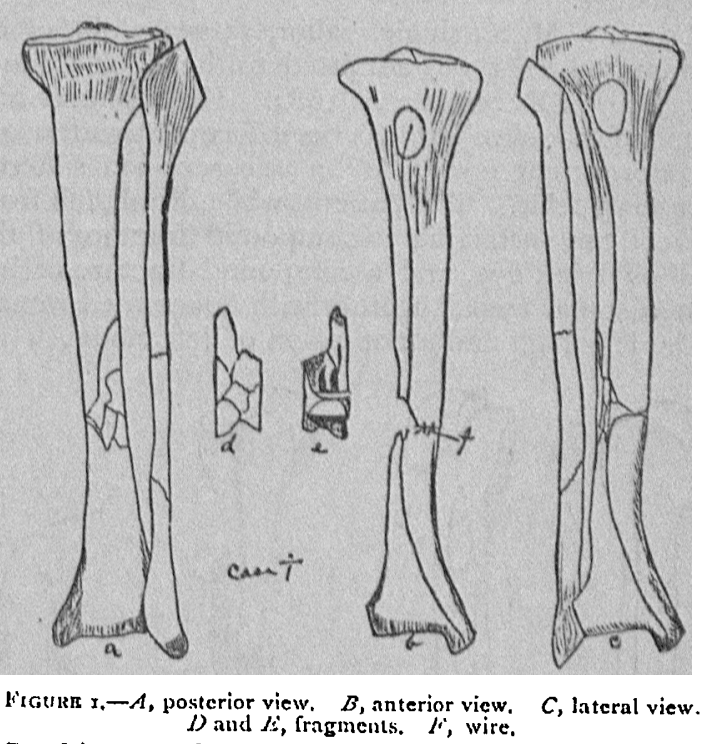

In this case the wound was enlarged upwarts and downwards with scissors until it was about five inches in length, and seven pieces of bone were removed. Two sharp points of bone were left at the junction of the lower and middle third of the tibia, which could not be retained in normal approximation. These points were thereupon removed sufficiently to secure such retention of normal approximation. 'The fragments were then wired together and dressed in the manner already described. 'The further progress of the case is well illustrated in the accompanying chart.

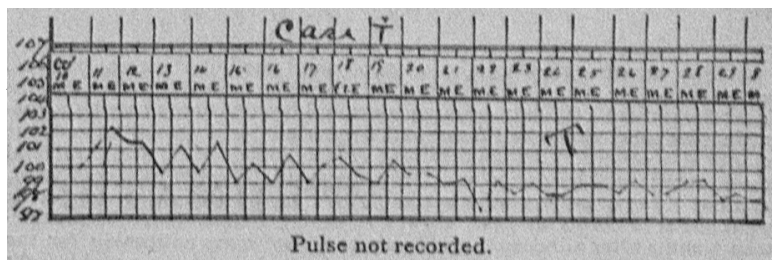

It may be said that from time to time small frag- 
ments of tissue came away. The fragments of bone approximated in the manner already described were denuded of periosteum; the upper fragment about an inch and a quarter and the lower about an inch; despite of this denudation, but little of either fragment exfoliated, as the denuded bone soon became permeated with blood-vessels and retained its vitality. There was no resection of the fibula; the upper fracture of the latter perfectly united; the lower fracture did not, and two months after admission the lower fragment was drilled and has since united. At present writing the patient seems likely to have a useful limb, without more than about half an inch of shortening. The limb in such a case would usually have been amputated, since the extent of the injury would have been considered too great to permit of repair for a useful limb. ${ }^{1}$

Second. Proper retention of the fragments in place is presumably secured, thus avoiding any possible danger of the fragments overriding and injuring the soft tissues.

Case 2.-M. S., single, sailor, 35 years old, of intemperate habits, was admitted to the Cook County Hospital on December 10, 1884. He has never had venereal troubles, but has been frequently attacked by intermittent fever, and on one occasion suffered from erysipelas. The patient, while drunk, fell from a street car, sustaining a compound fracture of the skull over left eye, and a compound fracture of left humerus near neck, together with a lacerated wound of the left thigh and a contusion of left elbow.

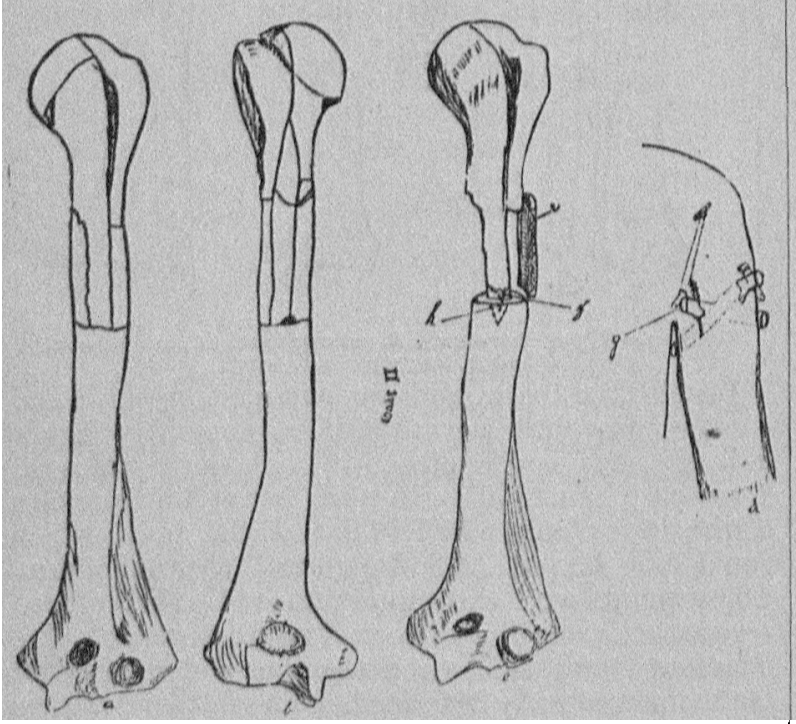

FIGURF 2.- $A$, anterior view, $B$, posterior view. $C$, anterior view. $D$, anterior view of soft parts. $E$, remaining fragment. $F$, dead bone re

1Two months after admission two small shell-like pieces of bone, which came one from each end, and the wire were removed. Two months later the patient left the hospital on pass and became intoxicated, refracturing the bonc, which had been well supported by " strong cast. One month sub eqe ent to this an inch was resected from each fragment and these were joined by one wire. Only one small drainage-tube was used, and but three dressings were needed. Di ring the next eight months he went out at intervals on pass, always returning intoxicated. About thirteen months after admission evidences of union were noticeable for the teen months after admission evidences of union were noticeable for the on the part of the patient without the aid of crutches. The les swelled
considcrably. Since that time union has gone on with groat rapidity.
The wounds were dressed and the fractures treated in the way already described. December II, his morning temperature was $100^{\circ} \mathrm{F}$, and his pulse roo; evening, 10 ${ }^{\circ} \mathrm{F}$., and the pulse $5_{50}$. $\mathrm{He}$ was given eggnog and alcoholic stimulants.

December I2, his morning pulse and temperature were $\mathrm{I} 45$ and $99^{\circ} \mathrm{F}$. Evening, I40 and $97.5^{\circ} \mathrm{F}$., and there were given three grains of quinine and ten minums of tincture of per-chloride of iron thrice daily, as well as one-twentieth of strychnix hypodermically. On December I 5 the leg was dressed; it looked well; no pus. On the I6th the arm was dressed and there was much discharge of an offensive character, because of sloughing of the soft parts.

December $2 \mathrm{I}$ the arm and leg were dressed and

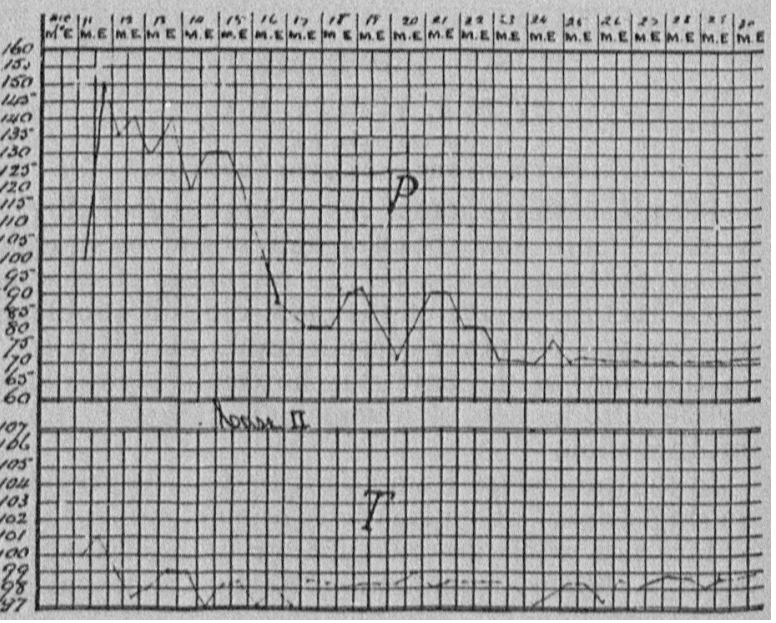

were looking well. At the present writing patient is able to move the arm, but owing to a wound (rendered necessary to remove a fragment of bone and wire) which has not healed, he still keeps his arm in a sling. Supination, pronation, flexion and extension are being regained by him. He can raise the arm to an angle of sixty degrees. There are no trophic or motor disturbances of the hand, which will show that no nerves have been permanently injured.

The advantages of the procedure are well illustrated in this case. One muscle, presumably the short head of the biceps, lay severed on the thorax. The fracture began transversely at the upper portion of middle fifth; then extended longitudinally through the capsule. About two inches of the upper fragment was fractured into four nearly equal parts; the most posterior fragment extended further upward in a.V shape than the rest; the most internal and posterior fragments were nearly denuded of periosteum, and were removed; the most anterior fragment was attached to the head of humerus, was partly denuded and was left for mechanical support; the remaining fragment was not denuded and was retained. The sharp corners of the anterior fragment were sawed off and it was inserted to the distance of half an inch in the medullary canal and wired; the other fragment

The limb has regained its usual contour. There is but two and a half inches shortening: the ankle is somewhat immobile, but this immobility is becoming less, and the pationt it able to walk short distances without a cane. 
was left free in close apposition. It will be obvious that in this case the fracture was one in which many surgeons would regard an amputation as an absolute necessity.' (See chart and figure 2.)

Third. There is no extension needed, which avoids the necessity of complicated apparatus and procedures such as too often interfere with proper antiseptic dressings.

Case 3.-J. C., aged 27; married; Irish; was injured August 30, 1884 , by a hand car from which he was thrown. He struck on one foot, the car running over leg. The tibia and fibula were fractured, and there was also an extensive contusion of integument and muscles. The same day he was admitted to hospital (twenty miles distant from the place where he was injured). The ends of the bones

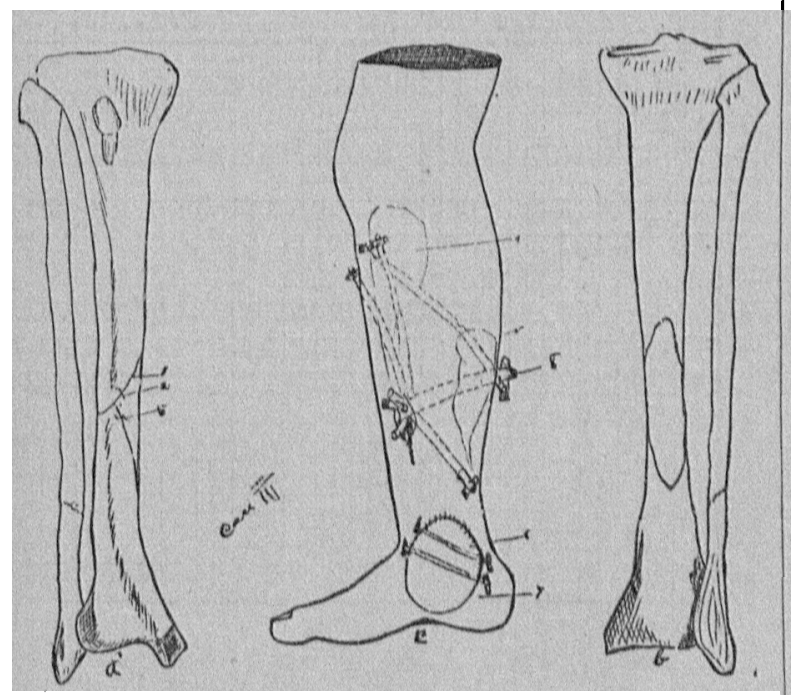

Figure 3,- anterior vicw. $B$, posterior vicw. $C$, lateral view soft parts. $5,2,3$, wires. 4,5 , blood cat vities bencath the stbcutancous tissue. 6, flap of soft parts. 7, position of soft parts on atimission. 8, drainage-tube.

protruded and were covered by coal dust. The fracture involved the lower part of the micldle third of the tibia, which was fractured in three portions; the smaller being triangular. A piece of bone an inch by half an inch was removed from the posterior part of tibia. As the contusion was extensive, seven drainage-tubes were inserted. The fragments were wired together. The triangular piece was wired to the upper by two wires which produced a notch or V-shaped depression into which the lower fragments fitted, to which it was then wired. The lower end of the upper fragment was denuded of periosteum. 'The temperature and pulse changes are best illustrated by the accompanying chart. The patient recovered perfectly without deformity, the shortening being less than one-eighth inch. The drainage prevented any extensive swelling of the tissues which must otherwise have

$1 \mathrm{June} 20,1885$, the patient was etherized and the depth of the pus pocket in the medullary canal detcrmined to be seven inches. The bone was trephined and a drainage-tube inserted at the lower termination of the pus pocket. The wound healed rapidly. The patient spent the summer and winter between Chicago and Milwaukec, and used the arm for many purposes. March, 3886, he returned to the hospita, and at his reguest two inches of bone were rusected in order to so approximate the Iragments as to secure union. After the operation the framents werc united by two wires and drainage-tubes inberted. There hns been tio fever. resulted in considerable discomfort, independently of its influence in preventing blood poisoning. (See bone chart.) I Iatter part of November patient walked about the ward and did light work.

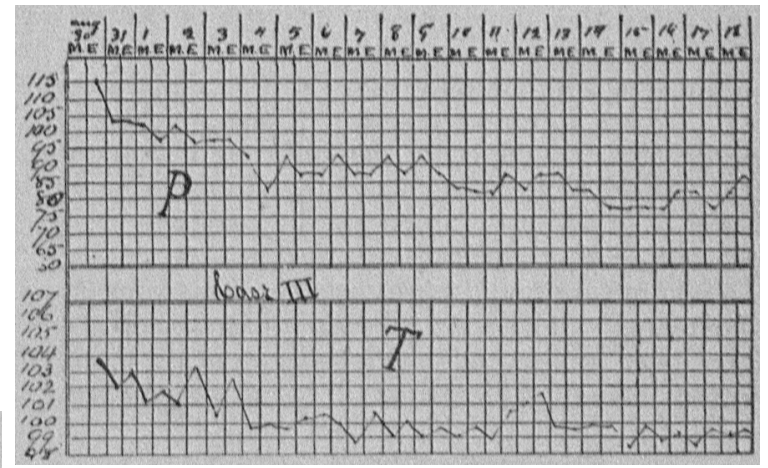

Fourth. The bones unite quicker, for reasons which will be obvious when the principles which underlie all procedures to secure union of ununited fractures are recollected.

Case 4.-I. S., cigar-maker; aged $5 \mathrm{I}$; moderate drinker; compound fracture of left leg. The tibia was fractured obliquely upwards and backwards, about junction of lower and middle third. The upper fragment protruded through the skin two inches and was denuded of periosteum to the extent of an inch and a half. The lower fragment extended upwards and backwards from two to four inches. The fibula was broken two inches above its lower extremity. The projecting point of bone was sawn off, as

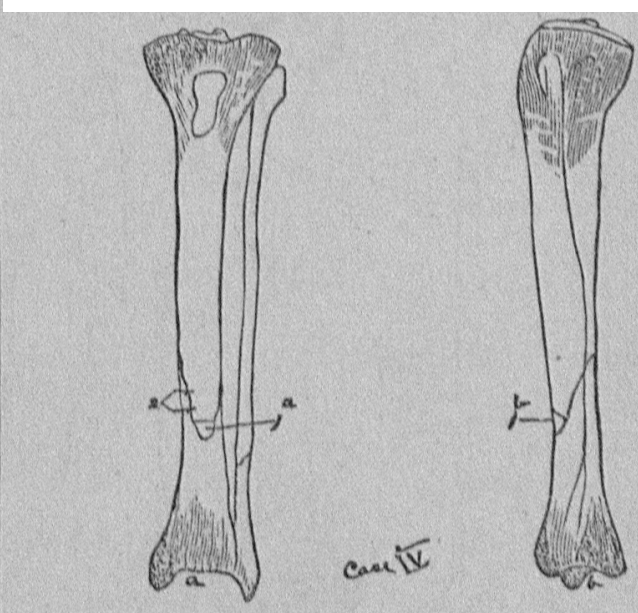

Figurn 4,- $A$, anterior vicw. $B$, lateral view. I $a, 1 b$, sharp point removed. 2, wires.

it was denuded, very sharp, and likely to injure the soft parts, and was not needed for support. The fragments were wired together (several blood clots had to be removed, as the soft parts were much contused), before twisting the wires. A drainage-tube was passed through the gastrocnemius. The limb was then dressed in the usual way. The patient recovered with one-fourth inch shortening.' (See fever and bone charts.)

\footnotetext{
1 Recovery resembled that from simple fracture. One-fourth of an
} inch shortening resulted. The man is working at his trado. 


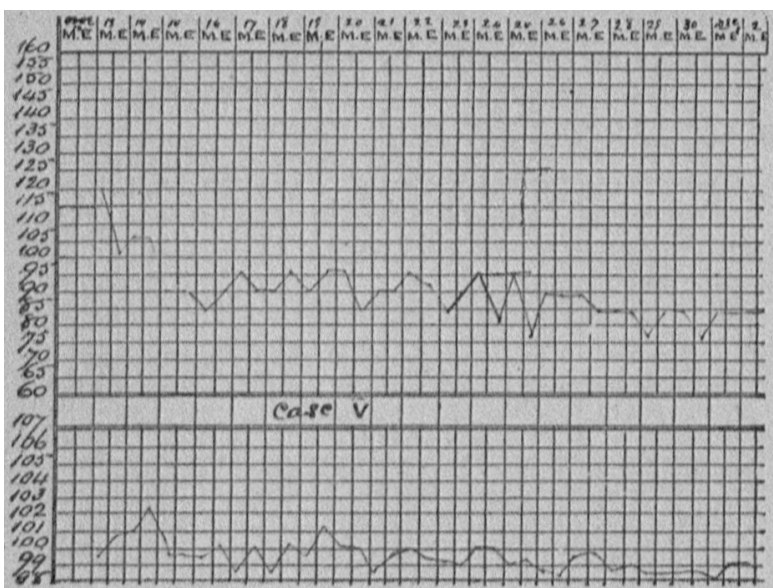

(Error in chart-should be marked IV.)

Fifth. As a rule, it will be apparent that there can be little if any shortening.

Case 5.-G. T. S., married; white; aged 41 ; weight 225 lbs.; heavy drinker; has had syphilis twenty years ago. Was admitted to the Cook County Hospital November 21, 1884, having fallen from a fifth story scaffolding and struck on one foot, causing a compound comminuted fracture of right leg. On examination it was found that the tibia was fractured obliquely (see cut 5), the line of fracture being four inches, and the fragments protruded markedly through the soft parts, which were very much lacerated.

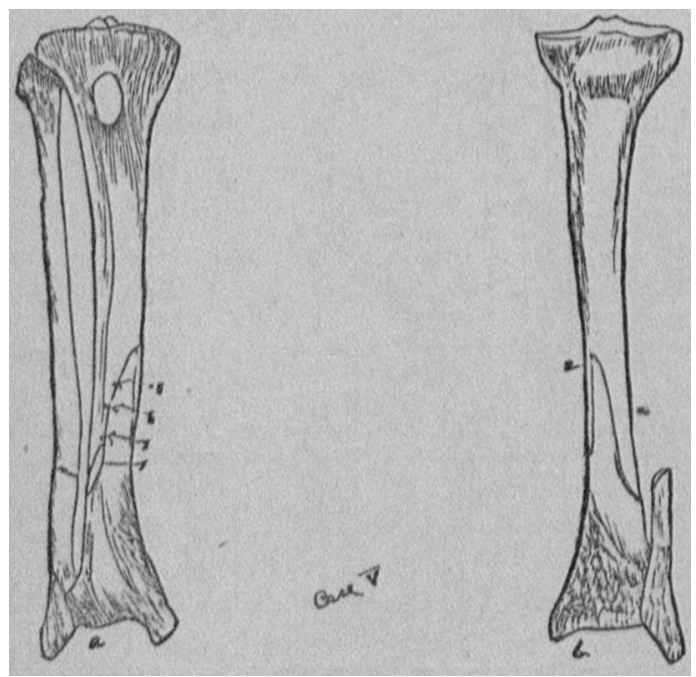

Figukl 5.- $A$, anterior view. $B$, posterior view. 1,2 , fragnents removed on admission. $5,6,7$, wires.

The fibula was fractured transversely and the foot could be bent at right angles with the leg without resistance. This was treated in the way already described, and the progress of the case towards recovery was only interrupted November 29, by a marked sloughing of tissues around the original wound, and on December I more sloughing occurred, causing the loss of substance, skin and cutaneous tissue in calf of leg three inches by four. The patient thereafter did well and was discharged nearly recovered April
I, there being a possibility of a small piece of bone to be removed.' (See figure and chart.)

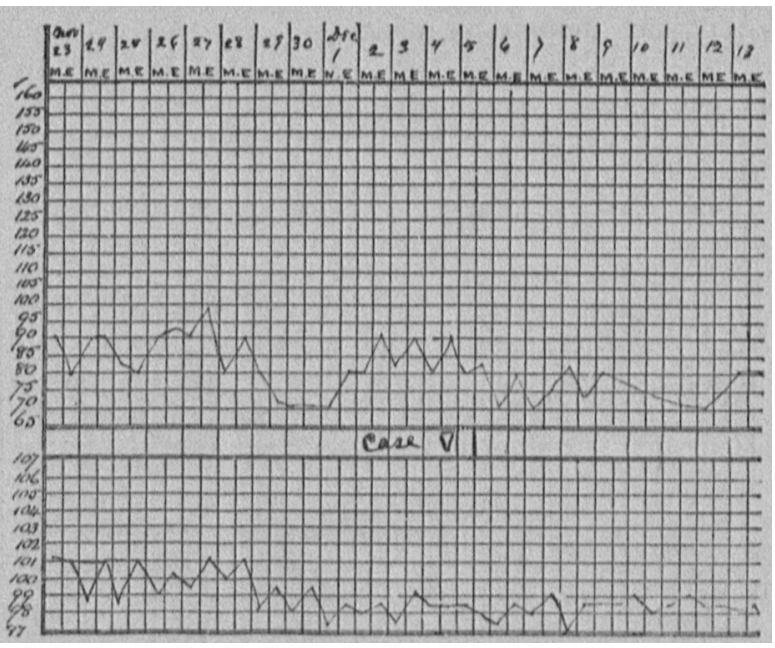

Sixth. Drainage prevents inflammation by preventing the accumulation of fluids, as in cases $I, 2$ and 3 .

Case 6.-A. S., aged 45 ; moderate drinker. In this case the left tibia was fractured as shown in cut VI, and there was a small external opening through the integument.

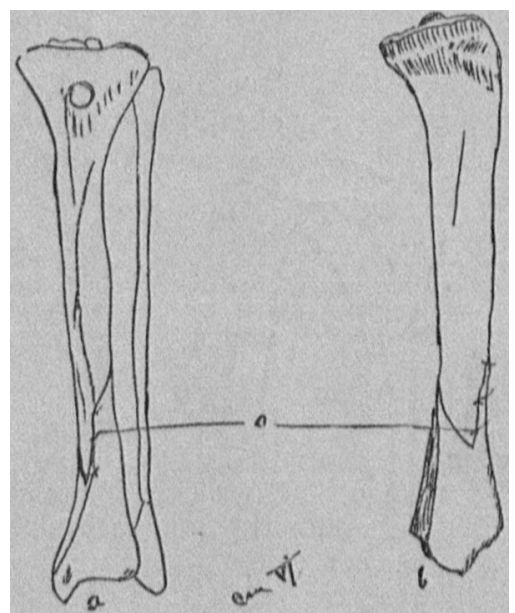

Figurg 6. $\rightarrow A$, anterior view, $B$, lateral view. $C$, wires.

The fragments were not comminuted, but an extensive hamorrhage which had occurred led to an enlargement of the external wound, and showed that the posterior tibial artery had been nearly severed by a sharp point of bone. The artery was tied and the fragments wired, and the wound treated in the usual

1 April, 2885 , patient left tle hospital against advice. There was an eighth of an inch shortening. There was a small opening. The limb had a good contour, and union was apparently good, as the leg would sustain much weight. The patient, a chronic inebriate, returned within three weeks auffering from erysipclas, which was followed by abscesses in thigh, knee-joint, and leg. lhe foot became markedly extended and ankle-joint limited in motion. Heot recane markedly extended and three wecks much emaciated. In an attempt to flex the foot the les was three weeks mich emaciated. In an attempt to flex the foot the leg was refractured. September, 1885 , the ends of the fragment were chiseled till the ends could be approximated and then joined by two nails. Good union followed. 'The leg tissues were flabby. He has since had three recurrent attacks of crysipelns. 'The leg muscles arc much emaciated. weight on the foot. Shurtening, one-half inch. 
way. Pyremic symptoms set in and were followed bullet, the wound healed by first intention. The paby symptoms of gangrene necessitating amputation, tient bids fair to nake an excellent recovery. ${ }^{1}$ after which the patient made a good recovery.'

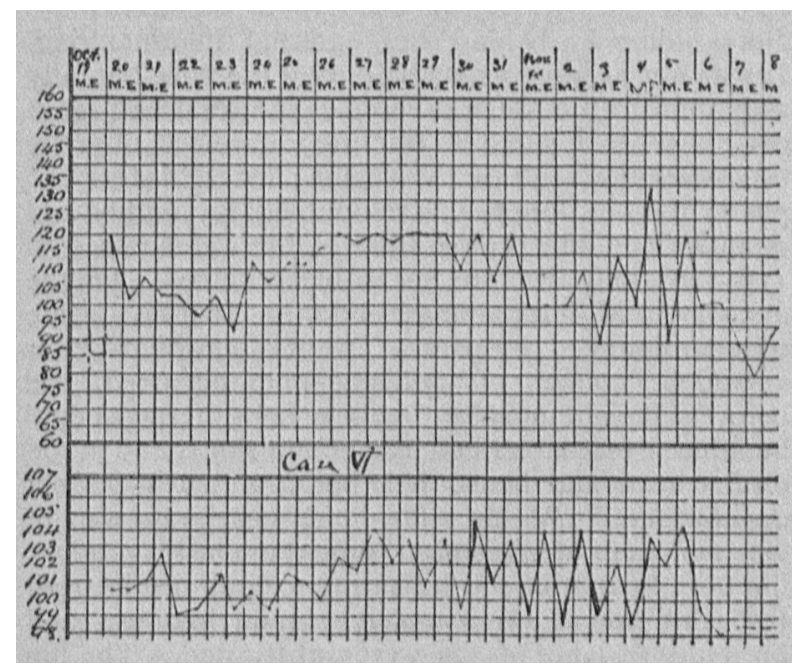

Case 7.-F. W. B., policeman; aged 27; moderate drinker; has had venereal disease; was shot in anterior part of left leg and after injury attempted to use limb. There was a circular opening about the size of a nickle, extending down to the bone, from which a slight active hxmorrhage occurred. The wound was over the left tibia about the lower part of the midclle third. The tibia was fractured in the way indicated in figure 7 . The upper fragment being split in two, and the fibula was also fractured.

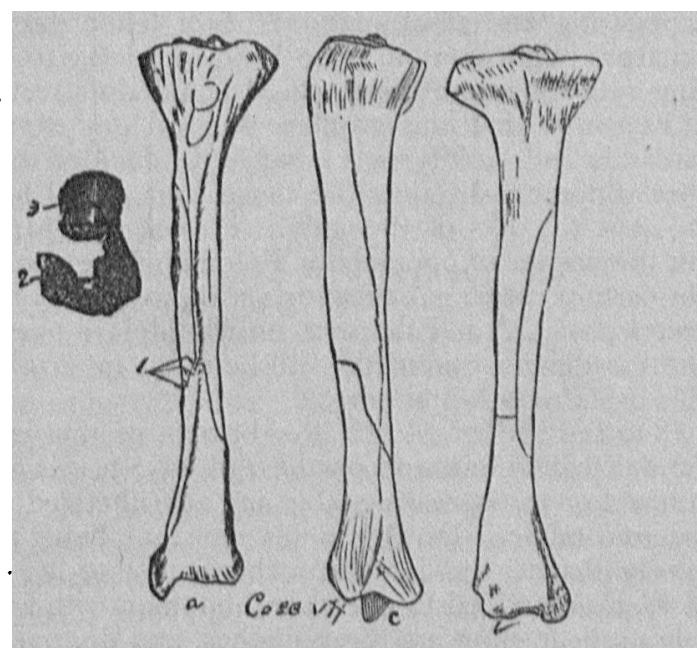

Figuka 7.- $A$, anterior view, $B$, posterior view, $C$, latoral view. t, wire. a, cloth. 3 bullet.

A longitudinal incision was made four and one-half inches in length, through the skin to the bone; the flattened bullet and a fragment of cloth lay about two inches from where the bullet struck. Very efficient drainage was made by a moderate sized tube. The fragments were then wired, as in Case 3. With the exception of the parts much contused by the

1 No further history obtuined.

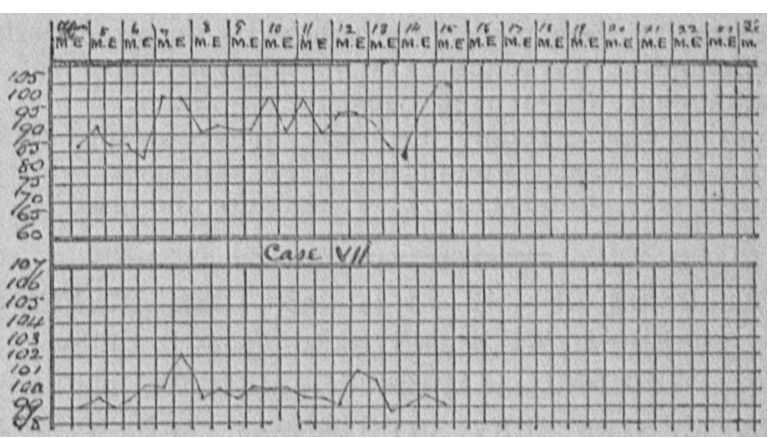

Case 8.-J. C., white; laborer; aged 40; fractured leg; (compound). The wound was at the lower third of the leg; the tibia was fractured into five pieces, and there was an oblique fracture of the fibula. The fracture communicated externally in three places.

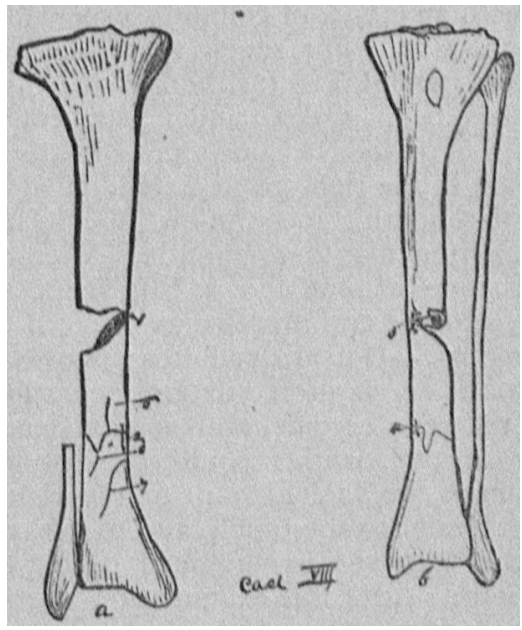

Ficura 8,-A, anterior view. $B$, posterior view. $1,2,3,4$, wires. 6 and 7 , fissures.

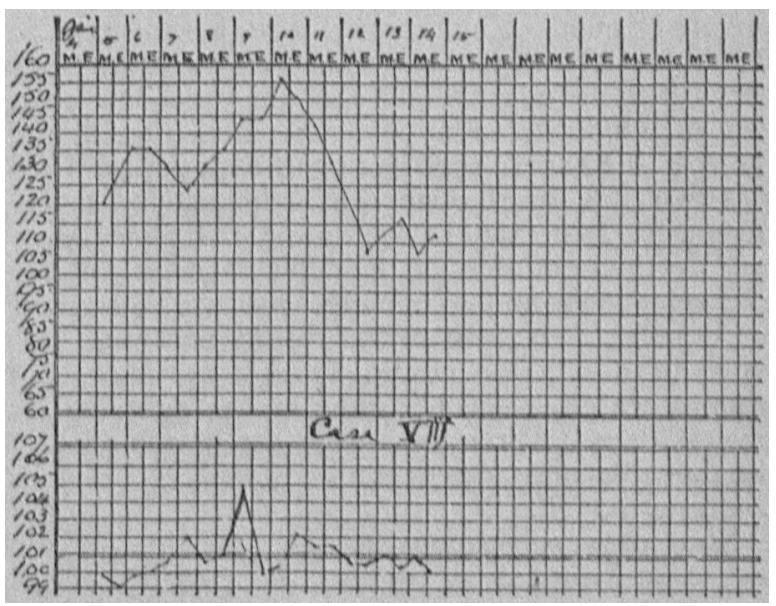

1 Recovered with between half and a third of an inch shortening. During my absence an attempt was made ti put on an interrupted cast 'The wires broke through, the fragments becane dislocated and numerous ulcers resulted from iron bur in cast. liragments re-approximated and re-wired. 
There were several loose pieces of bone removed and the parts surrounding the fracture were severely contused. 'The fragments were wired together, but extensive sloughing of the soft parts occurred and amputation was found to be necessary five days after admission; the patient dying five days later.

This case certainly does not militate against the procedure, as it would have been a desperate one under any circumistances. ${ }^{1}$ (See figure and chart).

OCCLUSION OF THE FALLOPIAN TUBE, DYSMENORRHEA, WITH CONVULSIONS AND OPISTHOTONOS-LAPAROTOMY; RECOVERY.

BY k. STANSBURY SUTton, A.M., M.D., L... D., Or pitrsaurci, BA.

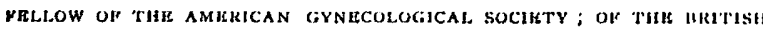
GYNHCOLOGICAI. SOCHTTY; ASSOCIATH WHLLOW OF THH PHH.A-

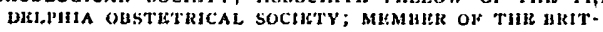

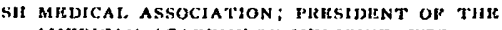
AMURICAN ACADHAY OF MEDICINE, UTC.

Mrs. R., an American lady, aged 31 years, was confined with her only child in 1876 . Her labor was followed with an attack of cellulitis, especially severe on the right side. For seven years her menstrual periods were painful, and for the last two and a half the pain has been accompanied with convulsions. Her menstrual periods became more and more trying, and the pain in the right groin extending down into the leg and rendering locomotion difficult, increased in intensity from month to month. After enduring this disturbance for nine and a half years, she consulted me near the end of 1885 .

Examination.-Dorsal decubitus; perineum, partial laceration; cervix uteri, bilateral laceration. Vaginal walls relaxed; cervical and vaginal leucorrhoea.

Neither of the ovaries could be distinctly felt. The portion of the vaginal vault on the right of the uterus was tender to the touch, and to this region she referred the pain she experienced during her menstrual periods. After this examination she returned home, and continued douches of hot water and counter-irritation over the right inguinal region until February 8 , r 886, when she became an inmate of my private hospital. She reported that her distress at the time of her menstrual periods had increased since her visit to me near the close of the preceding year. Ten days after her admission she menstruated, and the pain she experienced during this period resisted all reasonable doses of morphia administered subcutaneously. An examination during the flow discovered, in the right side of the pelvis, a mass as large as a guinea egg and extremely sensitive. Morphia, hot douches, local blisters and rest in bed were persisted in during the continuance of the flow, and when it ceased, it left her lame in her right leg for several days. Three days after the termination of the flow, the mass discovered a few days previous could not be felt.

Nine days subsequent to the cessation of the menses and after six of comfort, the pain in the right

1 The patient's breath, on admission, smelled of whisky, and during his entire hospital sirjourn he appeared dazed. The tissues were bleediag, but sloughing did not seem likely to occur; the shock from an amputation would havo been greater than from the procedure adopted. We had no post-mortem; urine was not tested; exact cause of death not known. inguinal region returned; it extended down the leg on that side and rendered locomotion difficult and painful. Bimanual examination revealed the mass again present, situated on the right of the uterus and almost directly behind the external inguinal ring. It was not as large as it was during the flow, but fully as painful to the touch. Three days later it had again disappeared. Churchill's tincture iodine was liberally used over the vault of the vagina; local blisters ap. plied; the hot douches were doubled in number and quantity and the temperature of the water raised to $115-120^{\circ}$, and absolute rest in bed required. On the morning of March i 4 her second menstrual flow came on unannounced by pain. 'T'wenty-four hours later a sudden invasion of agonizing pain occurred, and before sufficient morphia to relieve her sufferings could be administered, she had six convulsions, and stood on her head and heels, her body arcuate-perfect opisthotonos. Within a few hours nearly 2 grains of morphia were administered subcutaneously, producing no apparent effect. Fearing a fatal result from the exhibition of the narcotic, chloral hydrates and bromides in large doses were sulstituted. The hot douches were continued and a blister applied over the right inguinal region. The mass in the pelvis was now apparent to the tonch and very sensitive to pressure. On March 19, after four days of severe suffering, the flow ceased, and in three days more the mass in the pelvis had again disappeared.

Diagnosis.-I could make none. Chronic cellulitis, recurring attacks of acute cellulitis, or local peritonitis was evident; but why? Was there pus, or blood in the tube? Possibly; but why no evidence except the pain and the mass alternately appearing and disappearing? Her lencorrhoeal discharges might contain pus; I did not delay to examine with the microscope; this I could do afterwards. I reasoned that this trouble was of long standing, steadily and rapidly increasing, and I decided to open her abdomen, discover the cause, and do all I could to save the life of the lady. I agree with Mr. 'Tait in the matter of opening the abdomen for exploration in certain cases. A diagnosis without this is not always possible, and the surgeon who delays operation until a diagnosis is made, will be often in error, and his uscfulness is limited.

On the $22 \mathrm{~d}$ of March the lowels of this woman were cleaned out, and on the $23^{d}$, at 2 l.M., she was placed on the operating table and anasthetized by the second nurse. I)r. Stone, my assistant, being necessarily absent, I assigned my chief nurse to his place. I then proceeded to open the abdomen with an incision a little short of three inches, and discovering a difficult operation awaiting me, I lengthened the incision to five inches. Through this I turned the intestines out upon a towel above the upper angle of the opening, and gave them into the care of the nurse. An adhesion on the tip of the omentum was detached from something in the pelvis. I then discovered that the ovary and tube on the right side were firmly adherent to each other, to the broad ligament and the roof of the vagina; with great difficulty they were released with the fingers and drawn into view. The pedicle was secured with Tait's knot, and the ovary 